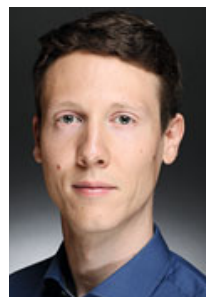

Marco Kühn

2009-2014 Biochemie- und Biologiestudium an den Universitäten Ulm und Marburg. 2014-2019 Promotion bei Prof. Dr. K. Thormann, Universität Gießen. Seit 2019 Postdoc bei Prof. Dr. A. Persat, EPFL Lausanne, Schweiz.

\section{VAAM-Promotionspreis 2020}

\section{Wie und warum Bakterien ihr Flagellum aufwickeln}

\author{
MARCO KÜHN \\ INSTITUT FÜR MIKROBIOLOGIE UND MOLEKULARBIOLOGIE, UNIVERSITÄT GIESSEN
}

DOI: $10.1007 / \mathrm{s} 12268-020-1373-7$

(C) Springer-Verlag GmbH 2020

Viele Bakterien nutzen rotierende, korkenzieherförmige Flagellen zum Schwimmen durch Flüssigkeiten. Diese Art der Fortbewegung wurde vor mehr als 100 Jahren entdeckt und wird bis heute erforscht. Wegen ihres geringen Durchmessers war es lange nicht möglich, das Verhalten einzelner Flagellen zu untersuchen. Erst Techniken zur Fluoreszenzmarkierung der Flagelline, den Bausteinen der Flagellen, erlaubten es, das Verhalten der Flagellen für ein breites Spektrum von Bakterien zu untersuchen.

In meiner Doktorarbeit wendete ich diese Technik an, um zu verstehen, wie sich Bakterien mit polaren Flagellen durch strukturierte Umgebungen wie Böden, Schleime und Gewebe fortbewegen. Dabei machten wir eine erstaunliche Beobachtung: Einige Zellen, die in engen Passagen zwischen zwei Oberflächen eingeklemmt sind, können sich durch einen bisher unbekannten Fortbewegungsmechanismus aus dieser Falle befreien. Beim Versuch, sich rückwärts aus der Engstelle zu ziehen, wickelt sich das Flagellum ruckartig um den Zellköper. In dieser schraubenartigen Konfiguration können sich die Zellen effizienter zwischen den Oberflächen fortbewegen [1].

Mithilfe unserer Kooperationspartner konnten wir zeigen, dass hydrodynamische Kräfte beim Rückwärtsschwimmen für das Aufwickeln verantwortlich sind. Der von uns vorgeschlagene Mechanismus ist universell und gilt sicherlich für viele polar flagellierte Bakterien. Tatsächlich wurde das Aufwickeln der Flagelle mittlerweile bei weiteren Bakterienspezies nachgewiesen, unter anderem bei Pseudomonas putida [2]. Diese Bakterien sind alle polar flagelliert und kommen in verschiedenen strukturierten Umgebungen vor.

Wie etwa die Hälfte aller flagellierten Bakterien baut unser Modellorganismus Shewanella putrefaciens sein Flagellum aus mehreren Flagellinen auf. Die Gründe dafür sind überwiegend unklar. Von einigen Bakterien ist bekannt, dass die einzelnen Flagelline klar abgetrennte Segmente im Flagellum bilden, so auch bei S. putrefaciens. Wir konnten zeigen, dass Shewanella dies durch eine schrittweise Produktion, Export und Einbau der beiden Flagelline erreicht. Aber welche Funktion hat diese Segmentierung des Flagellums?

Wir stellten Varianten des Flagellums her, die nur aus einem der beiden Flagelline beste-

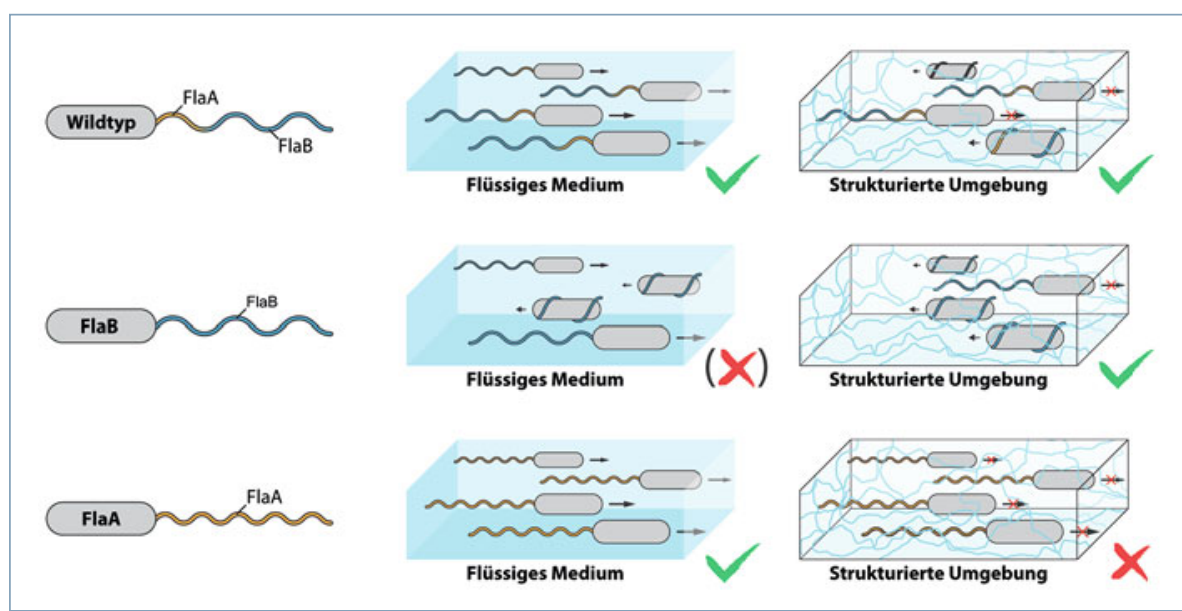

A Abb. 1: Das Flagellum von Shewanella putrefaciens kann sich um den Zellkörper wickeln und ermöglicht so eine effiziente schraubenartige Fortbewegung durch strukturierte Umgebungen. Durch den Einbau von zwei Flagellinen, FlaA und FlaB, mit unterschiedlichen physikalischen Eigenschaften ist es optimal für die Fortbewegung durch verschiedene Umgebungen angepasst. Filamente, die nur aus einem der beiden Flagelline bestehen, sind weniger gut für die Fortbewegung in flüssigem Medium bzw. strukturierten Umgebungen geeignet. hen. Beide Mutanten zeigen deutliche Einschränkungen bei der Fortbewegung, entweder in flüssigem Medium oder in strukturierten Umgebungen wie Weichagar (Abb. 1). Insbesondere können sich Flagellen, die nur aus dem Flagellin FlaA bestehen, nicht mehr um den Zellkörper wickeln. Der Wildtyp dagegen bewegt sich effizient in beiden Umgebungen fort. Der Aufbau aus zwei unterschiedlichen Flagellinsegmenten tariert also die physikalischen Eigenschaften des Flagellums so aus, dass der Wechsel zur schraubenartigen Fortbewegung nur unter bestimmten Bedingungen erfolgt, in denen diese Art der Fortbewegung auch nützlich ist [3].

\section{Danksagung}

Ich danke meinem Doktorvater Kai Thormann und dem ganzen Institut für Mikrobiologie der Universität Gießen. Besonders danken möchte ich auch unseren Kooperationspartnern um Bruno Eckhardt und Laurence Wilson der Universitäten Marburg bzw. York sowie der Deutschen Forschungsgemeinschaft für die Förderung dieses Projekts.

Lesen Sie mehr zu dem Thema im Wissenschaftsartikel von Marco Kühn und Kai Thormann auf S. 239.

\section{Literatur}

[1] Kühn MJ, Schmidt FK, Eckhardt B et al. (2017) Bacteria exploit a polymorphic instability of the flagellar filament to escape from traps. Proc Natl Acad Sci USA 114:6340-6345 [2] Hintsche M, Waljor V, Großmann R et al. (2017) A polar bundle of flagella can drive bacterial swimming by pushing, pulling, or coiling around the cell body. Sci Rep 7:16771 [3] Kühn MJ, Schmidt FK, Farthing NE et al. (2018) Spatial arrangement of several flagellins within bacterial flagella improves motility in different environments. Nat Commun 9:5369

\section{Korrespondenzadresse:}

Dr. Marco Kühn

Institute of Bioengineering and Global Health Institute

Ecole Polytechnique Fédérale de Lausanne

Station 19

$\mathrm{CH}-1015$ Lausanne

marco.kuhn@epfl.ch

Die VAAM dankt den Sponsoren der Promotionspreise: BASF SE, Bayer AG, New England Biolabs $\mathrm{GmbH}$ und Evonik Industries AG. 